\title{
EXPERIMENTAL ANALYSIS OF TIDAL NETWORK GROWTH AND DEVELOPMENT
}

\author{
Tesser G., L. Carniello, A. Defina, S. Lanzoni, F.M. Susin, and L. D’Alpaos \\ Department IMAGE, University of Padova, via Loredan, 20, 35131 Padova, Italy, \\ e-mail: giulia.tesser@unipd.it; carniello@idra.unipd.it; defina@idra.unipd.it; \\ lanzo@idra.unipd.it; susy@idra.unipd.it; dalpaos@idra.unipd.it
}

\begin{abstract}
In this paper we present some results of preliminary laboratory experiments carried out in a large experimental apparatus aimed at reproducing a typical lagoonal environment, subject to tidal forcings. We observed the growth and development of a tidal network and analyzed its most relevant features, taking into account the role played by the characteristics of the tidal forcings in driving the development of channelized patterns. Such an experiment was designed in order to improve our understanding of the main processes responsible for channel network ontogeny and evolution. Numerical and theoretical analyses of network configurations were also carried out through the use of simplified and complete morphodynamic models. In particular, we analyzed the evolution in time of the morphometric characteristics of the developed networks, and studied the hydrodynamics and sediment transport features related to a specific net configuration obtained with the experiments. The unchanneled flow lengths, compared to literature field data, have shown that tidal patterns developed within our laboratory experiment exhibit a behaviour consistent with that of actual tidal networks.
\end{abstract}

Keywords: lagoon, tide, experimental apparatus, tidal network

\section{INTRODUCTION}

Tidal channel networks exert a strong control on hydrodynamics, sediment transport, dynamics and nutrient exchanges within tidal environments, and therefore improving our understanding of their origins and evolution is deemed of central importance in order to address issues of conservation of such delicate systems.

A wide literature exists, developed especially in the last three decades, describing the hydrodynamics and morphodynamic evolution of tidal systems (see e.g., the review papers by Allen, 2000; and Friedrichs and Perry, 2001). However, in spite of their fundamental role in driving the morphologic evolution of tidal basins, only in the last few years mathematical and numerical models analyzing the morphogenesis and long-term morphological evolution of tidal channel networks have been proposed (Schuttelaars and de Swart, 2000; Lanzoni and Seminara, 2002; Fagherazzi and Furbish, 2001; Fagherazzi and Sun, 2004; D'Alpaos A. et al., 2005, 2007). Moreover, even though field observations on the development of tidal channel networks and conceptual models of network growth (Pestrong, 1965; Steel and Pye, 1997) have also been pursued, the description of the processes leading to the initiation and early incision of tidal channel networks still lacks a proper delineation. In particular, to our knowledge, no laboratory experiments exist which analyze the growth and development of tidal channel networks, except for a series of laboratory observations, recently carried out by Tambroni et al. (2005), which investigate the morphodynamic evolution of the bottom of a single straight tidal channel closed at one end and connected to a rectangular basin representing the sea at the other end. Towards the goal of gaining fundamental knowledge into the description of the main physical processes responsible for tidal channel initiation and 
network ontogeny, we carried out a series of laboratory experiments in a large experimental apparatus schematizing a typical lagoonal environment, subject to tidal forcings.

We furthermore used simplified and complete morphodynamic models to carry out numerical and theoretical analyses of the observed network configurations and, therefore, compare the relevant features of experimental and modelled morphologies.

The paper is organized as follows. Section 2 describes the experimental apparatus, Section 3 is devoted to the description of experimental-setup and of the associated results. In Section 4 we use simplified and complete hydrodynamic models to compare the morphometric features of the synthetic and observed channel networks. Finally, Section 5 draws a set of conclusions and some remarks on forthcoming developments.

\section{EXPERIMENTAL APPARATUS}

The experimental apparatus, schematically depicted in Figure 1, consists of two adjoining basins reproducing schematically the sea and the lagoon, respectively.

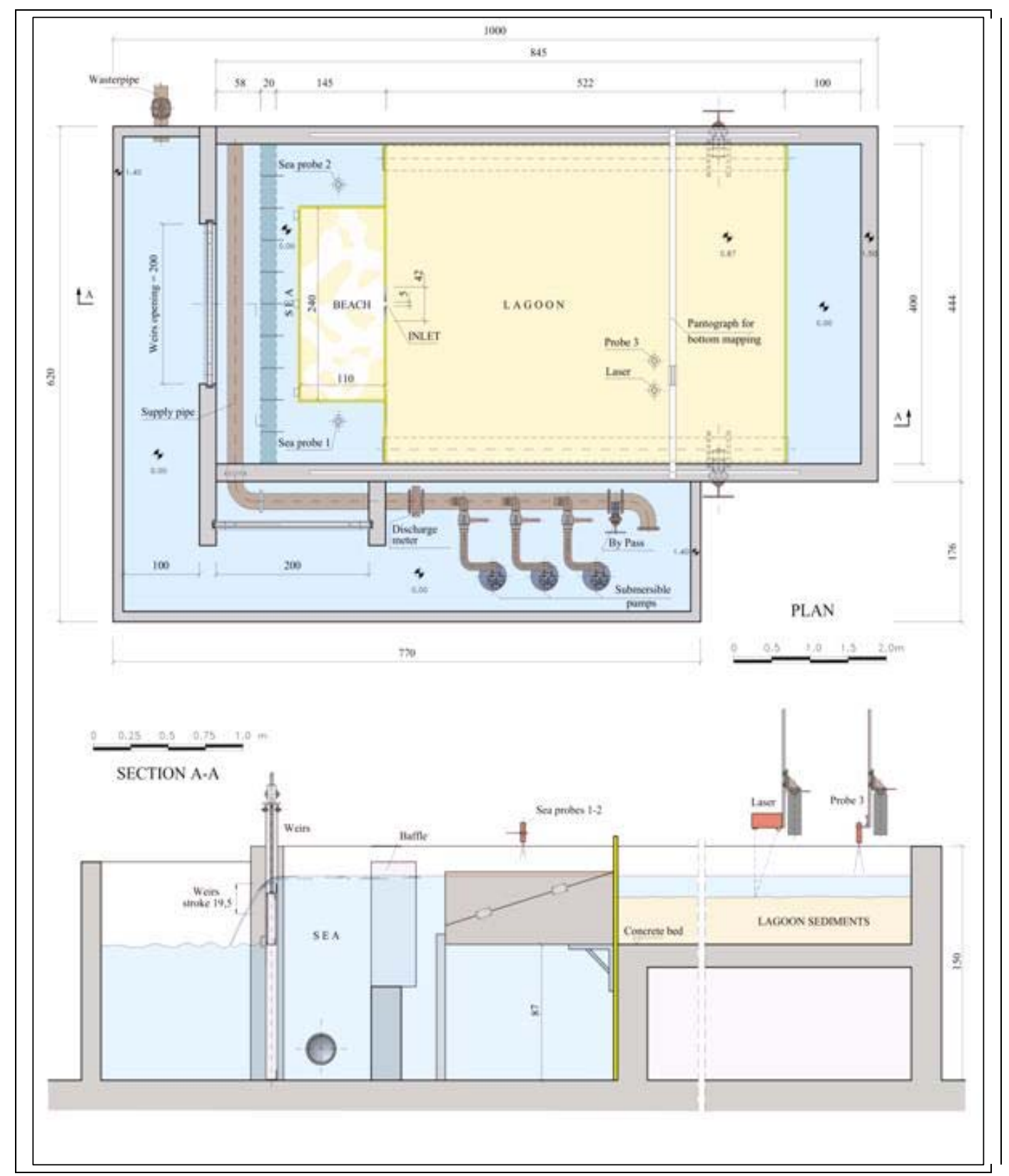

Figure 1: Sketch of the experimental apparatus. 
The basin reproducing the lagoon is $5.30 \times 4.00 \mathrm{~m}$ wide and its bottom is $0.87 \mathrm{~m}$ higher than that of the adjoining $1.60 \times 4.00 \mathrm{~m}$ sea-basin. At the beginning of experiments the lagoon surface is uniformly covered by a $0.30 \mathrm{~m}$ layer of sediments. A set of wooden panels separates the sea from the lagoon. The connection between the two basins is ensured by a 0.50 $\mathrm{m}$ wide rectangular-shaped inlet located along the longitudinal axis of the lagoon. In front of the inlet a shelf enables to reproduce the gentle slope of the sea bed.

The tide is generated at the sea by a vertical steel sharp-edge weir, oscillating vertically. The water continuously flowing over the weir is collected to a separated tank, where a set of pumps recirculates the flow.

A suitable software has been implemented to drive the weir. Given the amplitude, the period and mean sea level of the sinusoidal tide to be reproduced, the software continuously corrects the motion of the weir though a feedback process that uses the instantaneous water level at the sea measured by two ultrasound probes.

A computer-driven pantograph is adopted to measure the bottom elevation of the lagoon. The apparatus consists of a laser system (300 $\mu \mathrm{m}$ resolution) coupled with a sound probe measuring the bottom elevation and the associated water level, respectively. The latter measurement not only allows for the determination of local flow depth, but is also necessary to account for refractions effects on laser measurements induced by the presence of water. Indeed, to avoid undesired perturbations of bottom topography, the bathymetric survey of the lagoon is carried out without stopping the experiment and, therefore, also in presence of water.

The sediments used in the experiments are cohesionless plastic grains, characterized by a density of $1041 \mathrm{~kg} / \mathrm{m}^{3}$ and a median grain size $\mathrm{d}_{50}=0.8 \mathrm{~mm}$, as shown in the grain size distribution reported in Figure 2.

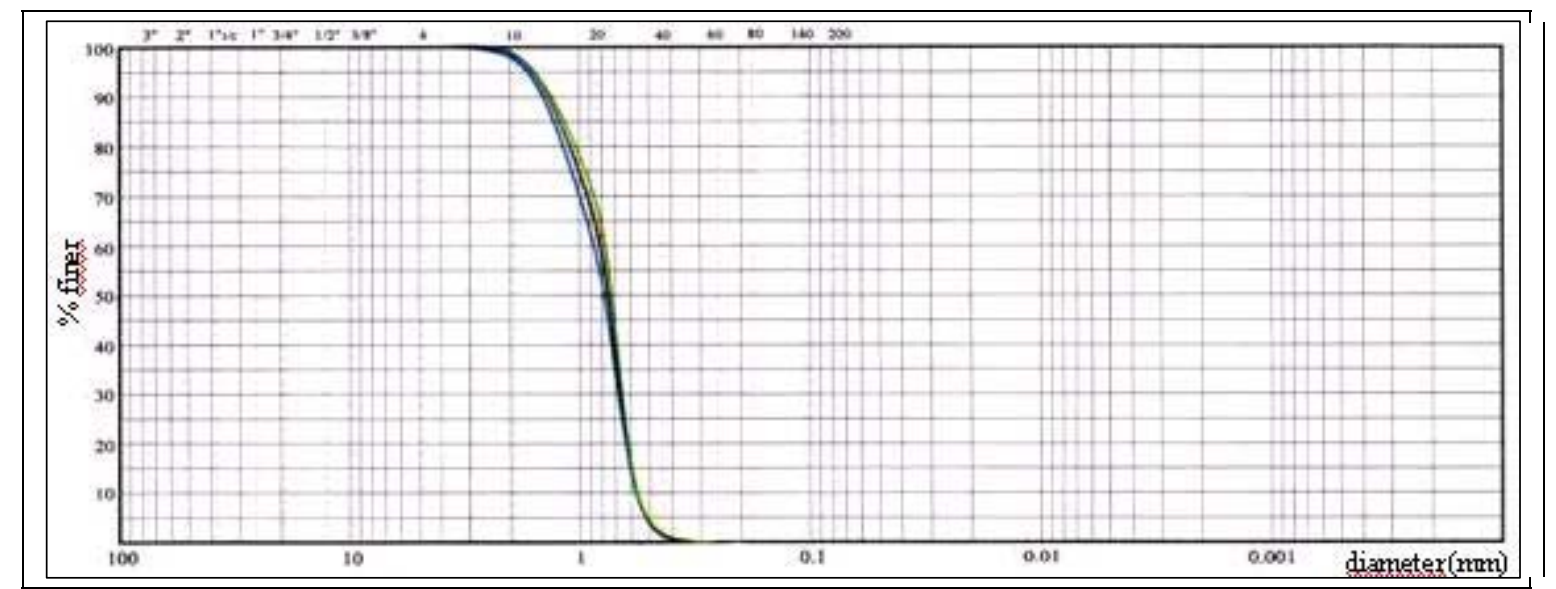

Figure 2: Grain size distribution of the sediments (cohesionless plastic grains)adopted in the experiments

\section{EXPERIMENTS}

Preliminary experiments have been carried out in so far, mainly aimed at indentifying proper conditions for a channel network to develop in the laboratory apparatus. To this end various tides (i.e., characterized by different amplitude, period and mean sea level) and different shapes and dimensions of the tidal inlet have been considered.

Experiments started forcing an initially flat lagoon bed with a given tidal wave. A tidal network was observed to form only for small enough values of the tidal amplitude (0.5-2.0 $\mathrm{cm})$ and of the flow depth $(1.0-2.0 \mathrm{~cm})$, related so that the mean sea level allows the draining of the sediment surface during the ebb phase. Moreover, a tidal period of 8-12 minutes was necessary in order to ensure a straight flow and to avoid perturbing vortex. In the presence of 
a too high tidal amplitude the sediments tended to be transported as suspended load, large dunes formed, and the growth of a channel network was inhibited. In any case, in all the experimental runs a quite wide scour, covered by dunes, formed at the inlet. The channel network was eventually observed to originate only from the landwards border of such a scoured region. It is also worthwhile to observe that bed load sediment transport was active during the whole experiment while ebb and flood peak velocities promoted suspended load along the channels. Finally, a common feature of all the experiments was the progressive net erosion experienced by the lagoon, leading to a reduction of its mean bottom level.

Prior to discuss experimental results, we describe in detail the evolution of the lagoon bed obtained during the most satisfactory experiment, characterized by a forcing tide having an amplitude of $2 \mathrm{~cm}$, a period of 8 minutes and a mean sea level coinciding with the initial average elevation of the lagoon surface. As pointed out before, a wide scour region rapidly formed near the inlet. After 220 tidal cycles some isolated channel started from the landward edges of the this scour region, beginning to cut the portions of the lagoon subject to draining. These channels progressively experienced a head cut-growth during the ebb phase and, after 500 tide cycles, some little ramification begun to form.

The lagoon configuration after 1200 tidal cycles, shown in Figure 3a, was characterized by four main, nearly straight channels originating from the inner border of the deeper region facing the inlet. The ramifications of these channels in some cases were unstable, i.e. a branch abandoned a main channel to join another one. Moreover, some smaller creeks migrated laterally, forming little meanders. After 2300 tide cycles, the main channels lengthened significantly and at 2800 tide cycles three evident meanders were observed to develop along one of these channels. However, the small scale bed forms (mainly dunes) initially located in the deeper scour area facing the inlet progressively extended throughout a larger portion of the lagoon, tending to destroy the channel network. In order to smooth out these undesired bed forms and, therefore, enhance the growth of a well defined channel network, we slightly decreased the mean sea level counteracting the progressive net reduction of the mean bottom level. Further experiments are required in order to quantify the proper rate of decrease of the mean sea level to be adopted. Figure $3 \mathrm{~b}$ shows the bed configuration obtained after 6000 tide cycles, when the experiment was stopped.

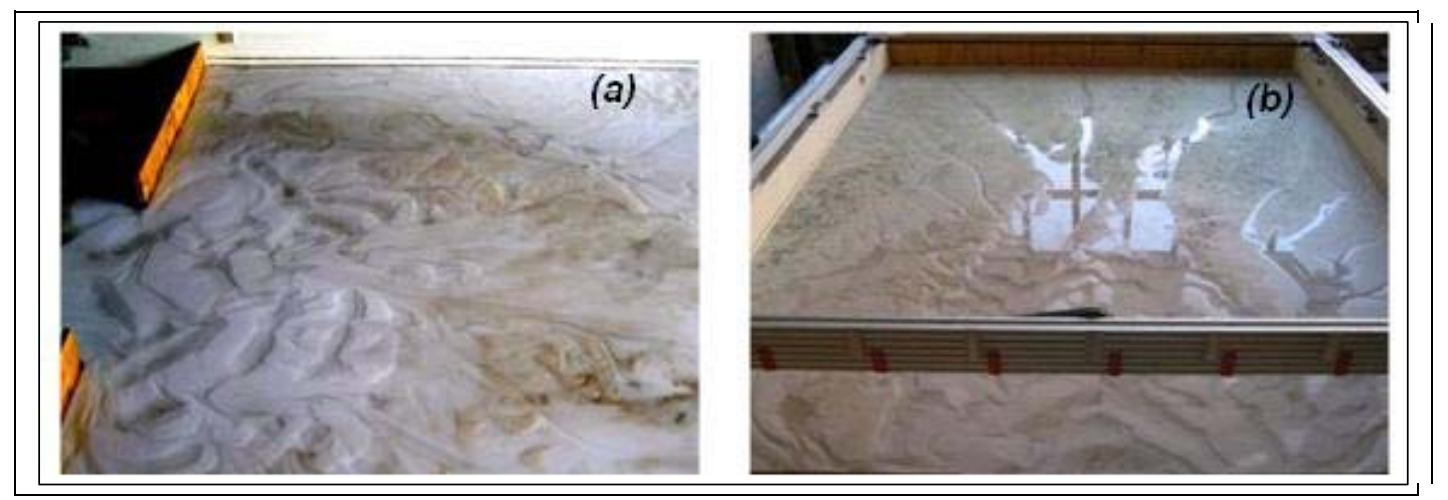

Figure 3: Lagoon topography observed after: a) 1200 and b) 6000 tidal cycles. Relevant parameters are: tidal amplitude $2 \mathrm{~cm}$; tidal period $8 \mathrm{~min}$. Notice that the mean sea level allows the draining of the sediment surface during the ebb phase.

\section{ANALYSIS OF EXPERIMENTAL DATA}

Bed elevations acquired by the laser system were used to produce topographic maps of the lagoon bottom surface at various times. Figure 4 shows the distribution of bottom 
elevation measured within the lagoon at four different instants during the experiment of Figure 3: the temporal evolution of channel network clearly emerges.

In order to analyse the presence of small and large-scale bed forms, which may affect net sediment transport and possible equilibrium morphologic configurations, the lagoon topography measured at the end of the experiment (i.e., after 6000 tidal cycles) was used to simulate numerically the flow field. To this end we adopted a semi-implicit staggered finite element model, based on Galerkin's approach, which solves the two-dimensional shallow water equations modified to deal with wetting and drying processes in very irregular domains. The reader is referred to D'Alpaos and Defina (1995), Defina (2000), D'Alpaos and Defina (2006) for details.

The simulation of the flow field characterizing the final experimental bottom configuration was carried out assuming a Gauckler-Strickler friction coefficient equal to 30 $\mathrm{m}^{1 / 3} \mathrm{~s}^{-1}$. The instantaneous water depth, velocity and bottom shear stress were computed. The calculations clearly indicate that the higher values of both velocity $U(\sim 3.7 \mathrm{~cm} / \mathrm{s})$ and bed shear stress $\tau(\sim 0.091 \mathrm{~Pa})$ were attained during the ebb phase at the deeper area which formed in front of the inlet, and at the first reaches of the channels departing from it. Secondary channel ramifications exhibited lower values of $U(\sim 2 \mathrm{~cm} / \mathrm{s})$ and $\tau(\sim 0.0002 \mathrm{~Pa})$.

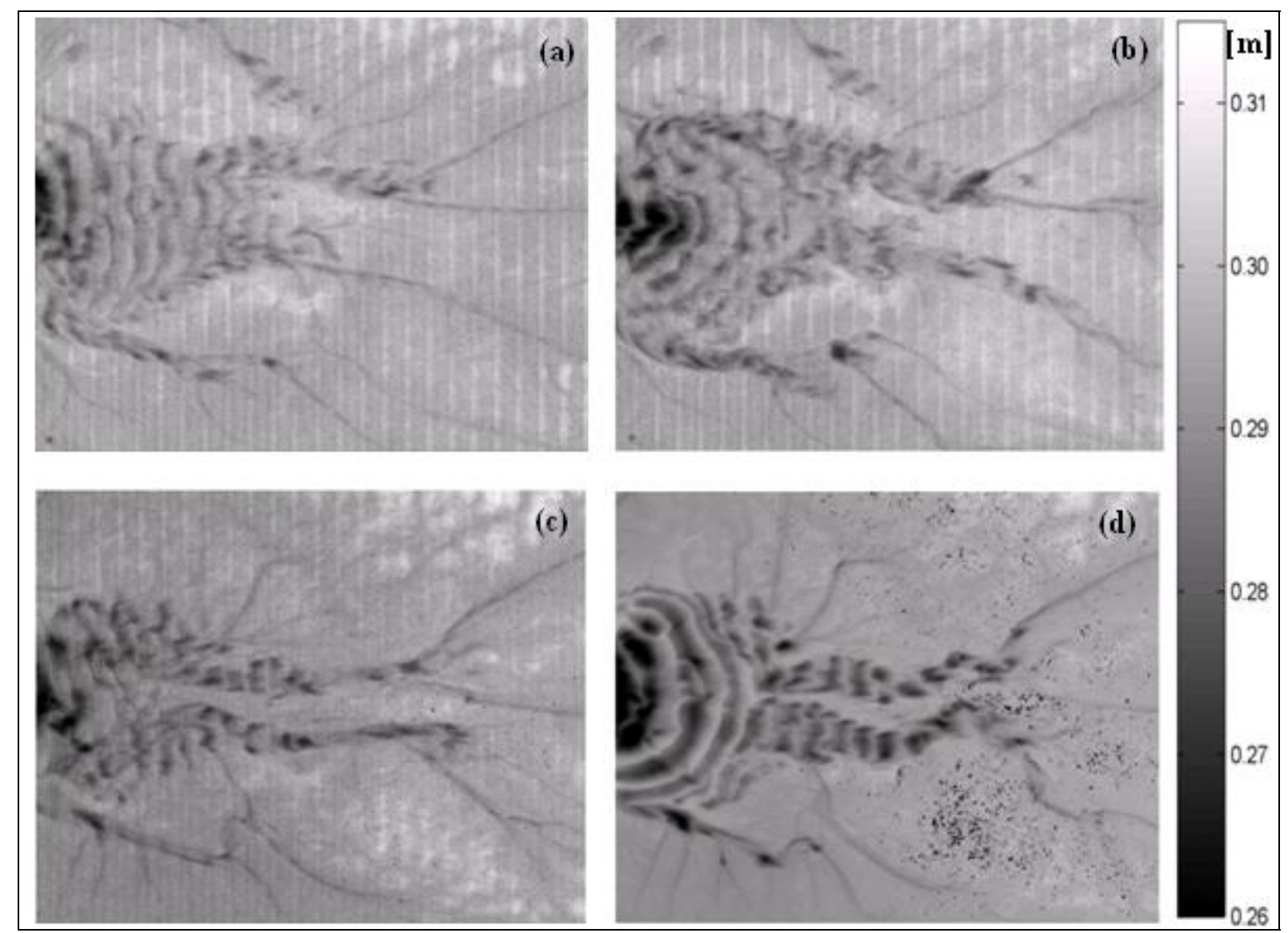

Figure 4: Distribution of bottom elevations measured within the lagoon after: a) 1650 tidal cycles; b) 2900 tidal cycles; c) 3910 tidal cycles; d) 6000 tidal cycles. Boundary conditions as those of Figure 3.

In order to evaluate the reliability of these results we calculated the dimensionless Shields stress $\tau^{*}$ and the particle Reynolds number Rp defined as: 


$$
\tau^{*}=\frac{\tau_{0}}{\left(\gamma_{s}-\gamma\right) \cdot d}=\frac{u^{* 2}}{\Delta \cdot g \cdot d}
$$

$$
R p=\frac{\sqrt{\Delta \cdot g \cdot d^{3}}}{v}
$$

where $\tau_{0}$ is the bottom shear stress, $d$ is the sediment grain diameter, $\gamma$ and $\gamma_{\mathrm{s}}$ are water and sediment specific weight, respectively, $\mathrm{u}^{*}=\left(\tau_{0} / \rho\right)^{1 / 2}$ is the friction velocity, $\nu$ and $\mu$ are dynamic and kinematic water viscosity, $\rho$ is water density, $\Delta=\left(\rho_{\mathrm{s}}-\rho\right) / \rho$ is relative density of submerged sediment, and $g$ is gravity.

Figure 5 shows the spatial distribution of the Shields stress during the ebb phase, i.e. when the bed shear stress attains its maximum value. In the Figure the critical value $\tau_{c r}^{*}$ for incipient sediment movement is also reported, evaluated as (Brownlie, 1981):

$$
\tau_{c r}^{*}=0.22 \cdot R p^{-0.6}+0.06 \cdot \exp \left(-17.77 \cdot R p^{-0.6}\right)
$$

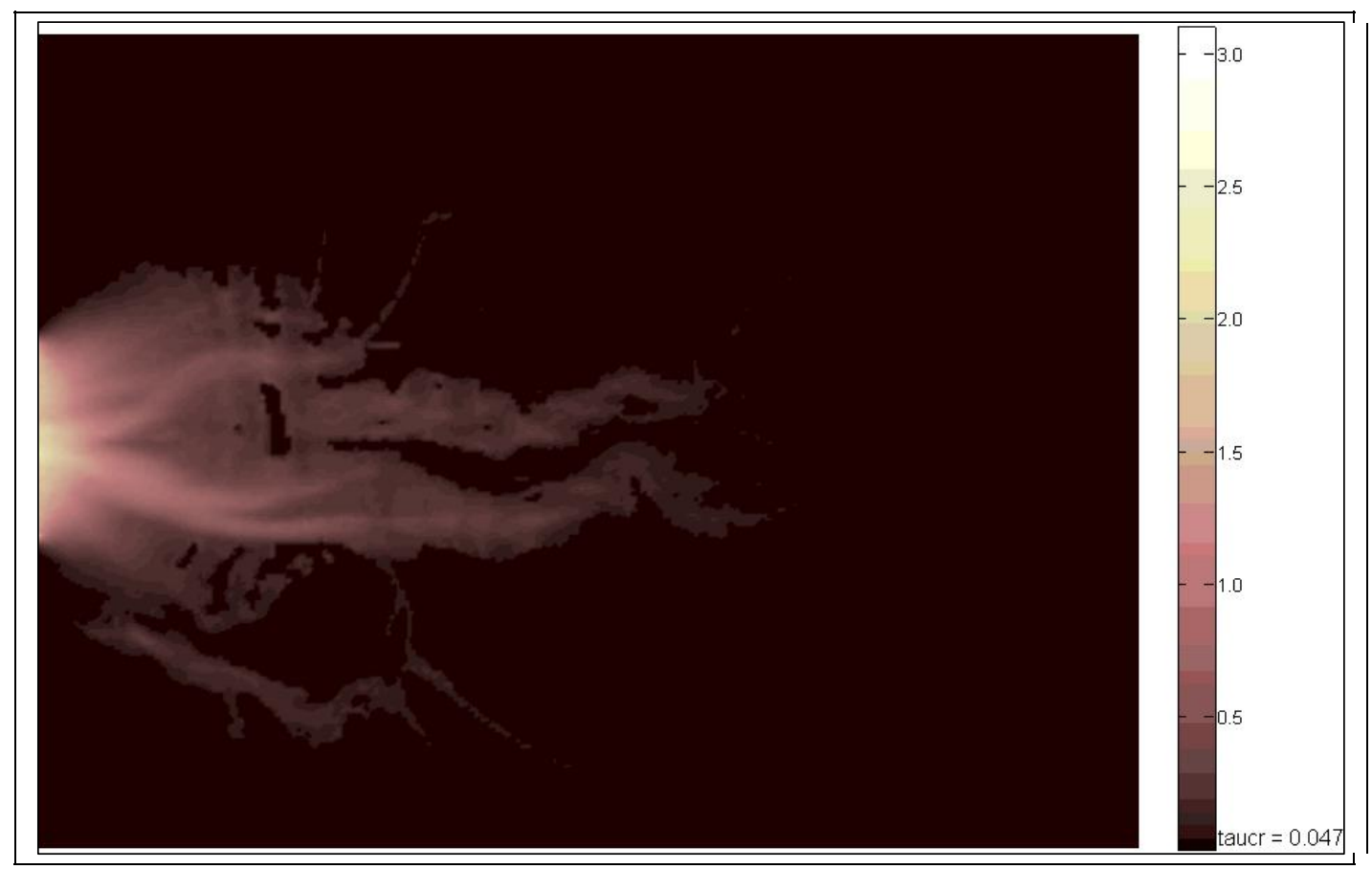

Figure 5: Spatial distribution of the computed excess Shield stress, $\tau^{*} . d_{50}=0.8 \mathrm{~mm}$.

Boundary conditions as those of Figure 3. Bottom topography as in Figure 4, panel d. $\tau_{c r}^{*}=0.047 \mathrm{~Pa}$, as given by equation (2).

It clearly appears that a large portion of the lagoon bed is subject to sediment transport. Some additional calculations performed adopting $\mathrm{d}_{10}$ and $\mathrm{d}_{90}$ in equation (2), respectively (see Figure 2), showed that the percentage of lagoon surface interested by sediment transport does not significantly modify.

Spatial distribution of bed forms (ripples and dunes) in the lagoon was evaluated according to the criterion proposed by Simon and Richardson (1966) on the basis of computed Rp and $\tau^{*}$. Figure 6 compares computed and observed spatial distribution of bed forms. Quite a good agreement appears.

Some details of the observed bed forms are shown in Figure 7. As previously pointed out, dunes tended to form in the scoured zone facing the inlet and in the first reaches of the main channels. The wavelength of these dunes, ranging about $20 \mathrm{~cm}$, is in accordance with predictions given by the empirical relationships proposed by Van Rjin $\left(\lambda_{\mathrm{d}} \approx 6 \mathrm{D}\right)$ and Yalin $\left(\lambda_{\mathrm{d}} \approx 7.3 \mathrm{D}\right)$ (Van Rjin, 1984a, 1984b, 1984c; Yalin, 1977; Yalin and Ferreira, 2001) since the mean flow depth $\mathrm{D}$ in the portions of lagoon covered by dunes was about $3 \mathrm{~cm}$. 


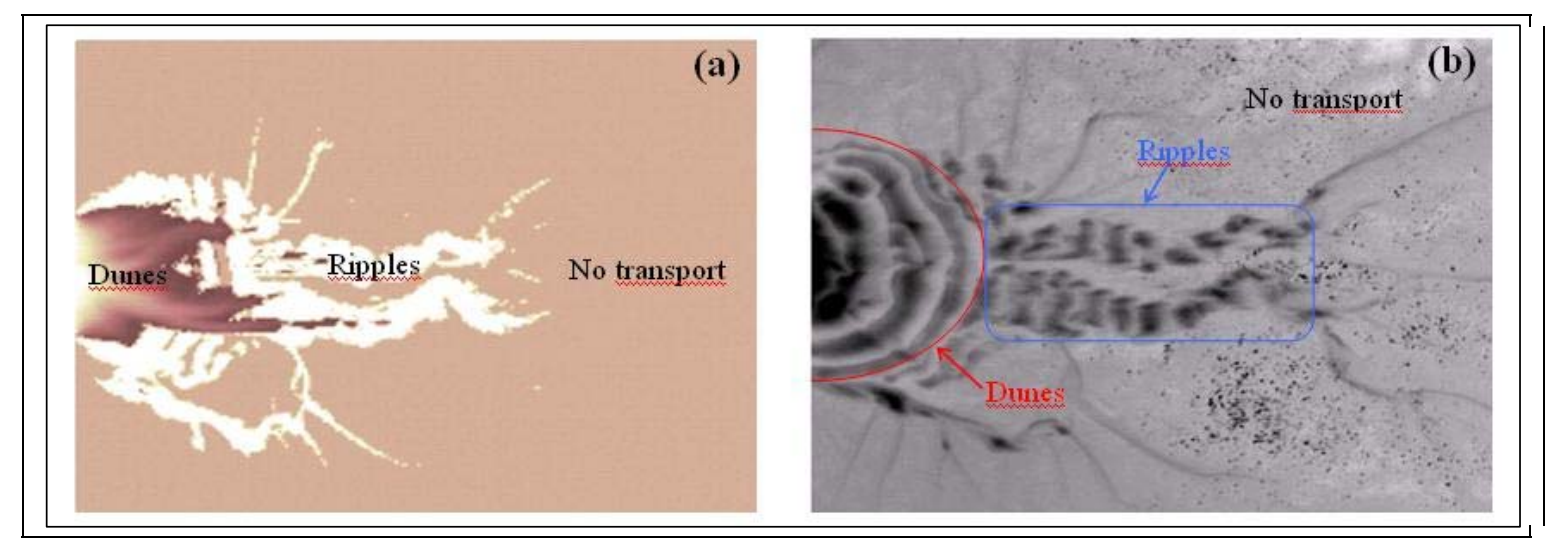

Figure 6: Spatial distribution of bed forms a) predicted following the Simons and Richardson(1966) criterion, and b) arising from experimental observations interpreted using geometric criteria (see Figure 7 for length scales).

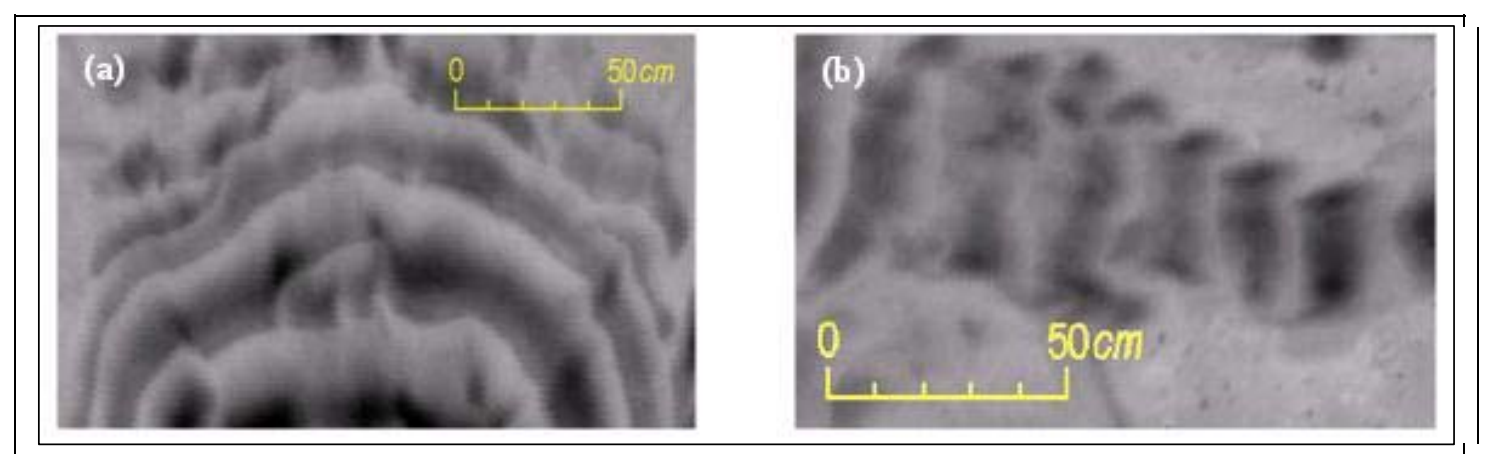

Figure 7: Features of the observed bed forms: (a) dunes forming in the deeper scoured area facing the inlet; (b) ripples growing within a main channel.

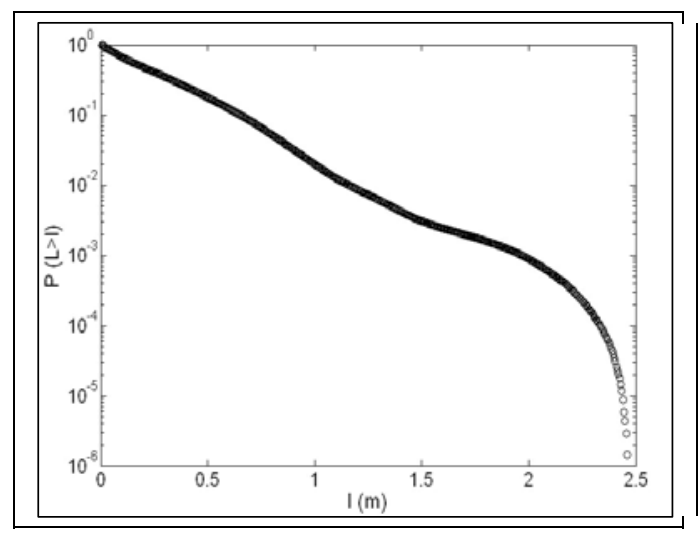

Figure 8: Probability distribution of unchanneled lengths. Bottom topography as in Figure 4, panel d

A further analysis involved the features of the experimental channel network. To this end, the planar configuration of the channel network was digitalized and analysed through the objective procedure developed by Marani et al. (2003). Such a procedure relies on a suitably simplified model of the flow field, which allows one to determine the hydrodynamic flow path connecting any unchanneled site to the nearest tidal channel and to compute its length, 1 . The probability distributions of unchanneled flow lengths computed for several tidal networks observed in the field (i.e., in the Venice lagoon) is typically characterized by a tendency to develop exponential decays, thus suggesting the absence of scale-free network features. As 
shown in Figure 8, the probability distribution of unchanneled lengths tends to decay exponentially also in the case of laboratory generated tidal network described in the present contribution.

\section{CONCLUSIONS}

Preliminary laboratory experiments aimed at the production of a tidal channel network have been presented.

Starting from an initially flat and horizontal bed, tidal networks were observed to form in the physical model provided that i) both the tidal amplitude and the flow depth are small enough (i.e., $0.5-1.0 \mathrm{~cm}$ and $1.0-2.0 \mathrm{~cm}$, respectively); ii) the mean sea level allows the draining of the bottom during the ebb phase; iii) the tidal period ranges between 8 and 12 minutes. Higher flow depths were seen to enhance the formation of bed forms (ripples and dunes) and to prevent the formation of well defined channels.

Results described in the present contribution are encouraging, confirming that a reliable tidal channel network can be produced in our apparatus following the proper experimental procedure.

Several points will be hence addressed in future developments of the research. In particular, the role of the shape, dimension and location of the tidal inlet will be investigated. The effects of channel network features associated to the initial configuration (plane in the present experiments) will also be analysed, possibly accounting for the random irregularities that likely characterize the bottom of real tidal flats. Further experiments are also required to infer statistics of the geometric characteristics of tidal channels (e.g., width B, depth D) and to find possible relations among them. The analysis of sediment cohesion, typical of lagoonal environments, is deemed of importance as well. Finally, the study of the influence exerted by different boundary conditions, e.g., an external supply of sediments to the lagoon, deserves further attention.

\section{AKNOWLEDGMENTS}

CORILA and the Comune of Venice are gratefully acknowledged. A special thank is due to Francesco Zanovello for his valuable help in the experimental work and in the analysis of the collected data.

\section{REFERENCES}

Allen, J. R. L. (2000), Morphodynamics of Holocene salt marshes: a review sketch from the Atlantic and Southern North Sea coasts of Europe, Quat. Sci. Rev., 19 (17-18), 1155-1231.

D'Alpaos, A., S. Lanzoni, M. Marani, S. Fagherazzi, and A. Rinaldo (2005), Tidal network ontogeny: channel initation and early development, J. Geophys. Res., 110, F02001, doi:10.1029/2004JF000182.

D'Alpaos, A., S. Lanzoni, M. Marani, and A. Rinaldo (2007), Landscape evolution in tidal embayments: Modeling the interplay of erosion, sedimentation and vegetation dynamics, $J$. Geophys. Res., 112, doi:10.1029/2006JF000537.

D'Alpaos, L., Defina, A.(1995), Modellazione matematica del comportamento idrodinamico delle zone di barena solcate da una rete di canali minori, Istituto Veneto di SS.LL.AA., Rapporti e studi, Vol. XII, 353-372.

D'Alpaos, L., Defina, A.(2006), Mathematical modeling of tidal hydrodynamics in shallow lagoons: A review of open issues and applications to the Venice lagoon, Computer \& Geoscience, doi:10.1016/j.cageo.2006.07.009.

Defina, A. (2000), Two dimensional shallow flow equations for partially dry area, Water Resources Research, 36 (11), 3251-3264. 
Fagherazzi, S., and D. J. Furbish (2001), On the shape and widening of salt-marsh creeks, $J$. Geophys. Res., 106(C1), 991-1003.

Fagherazzi, S., and T. Sun (2004), A stochastic model for the formation of channel networks in tidal marshes, Geophys. Res. Lett., 31, doi:10.1029/2004GL020965.

Friedrichs, C. T., and J. E. Perry (2001), Tidal salt marsh morphodynamics, J. Coastal Res., 11(4), 1062-1074.

Lanzoni, S., and G. Seminara (2002), Long-term evolution and morphodynamic equilibrium of tidal channels, J. Geophys. Res., 107(C1), 3001, doi:10.1029/2000JC000468.

Marani, M., Lanzoni, S., Belluco, E., D’Alpaos, A., Defina, A., Rinaldo, A. (2003), On the drainage density of tidal networks, Water Resources Research 39 (2), 105-113.

Pestrong, R. (1965), The development of drainage patterns on tidal marshes, Stanford Univ. Publ. Geol. Sci., Tech. Rep. 10, 87pp.

Schuttelaars, H. M., and H. E. de Swart (2000), Multiple morphodynamic equilibria in tidal embayments , J. Geoph. Res., 105, 24, 10524,118.

Steel, T. J., and K. Pye (1997), The development of salt marsh tidal creek networks: evidence from the UK, paper presented at Canadian Coastal Conference, Can. Coastal Sci. and Eng. Assoc., Guelph, Ontario, Vol. 1, 267-280.

Tambroni, N., M. Bolla Pittaluga and G. Seminara (2005), Laboratory observations of the morphodynamic evolution of tidal channels and tidal inlets, J. Geophys. Res., 110, F04009, doi:10.1029/2004JF000243.

Van Rijn, L. C. (1984a), Sediment transport. Part I: bed load transport. Journal of Hydraulic Engineering 110 (11), 1613-1641.

Van Rijn, L. C. (1984b), Sediment transport. Part II: suspended load transport. Journal of Hydraulic Engineering 110 (11), 1613-1641.

Van Rijn, L. C. (1984c), Sediment transport. Part III: bed forms and alluvial roughness. Journal of Hydraulic Engineering 110 (11), 1613-1641.

Yalin, M. S. (1977), Mechanics of sediment transport. Pergamon Press, Oxford.

Yalin, M. S., Ferreira da Silva, A. M. (2001), Fluvial processes, Queen's University, Kingston, Canada. 